\title{
Influence of Attitudinal belief on e-learning behavior among academics in state universities of Sri Lanka
}

\author{
Mohamed Majeed Mashroofa, Mazuki Jusoh, Karuthan Chinna
}

\begin{abstract}
The objective of this paper is to investigate the influence of attitudinal belief of "Decomposed Theory of Planned Behavior” (DTPB) on actual e-learning behavior among university academics in Sri Lanka.

The study applied a quantitative method by using questionnaire to collect data among university academics. Explorative and Confirmatory Factor analysis was used to examine the reliability and validity. And this study carried out Structural Equation Modeling to assess model fit and through path analysis, the association between variables was investigated. The study resulted that perceived ease of use, perceived usefulness, compatibility, attitude, behavioural intentions and actual behaviour met the indices for model fit. The findings showed perceived usefulness and perceived ease of use associated with attitude while compatibility is not. Attitude significantly and positively associated with behavioural intention. While behavioural intention positively associated with the actual usage this mediates the relationship between attitude and actual behaviour. The e-learning usage of academicians will help to enhance the quality of higher education system in Sri Lanka as well as to magnify the number of university intake as the country seeks to achieve its vision to be "the knowledge hub in the region and a leader in higher education in Asia by 2020". Though the e-learning adoption studies are growing trend of education and system researchers as evidenced by extant literature, studies on attitude and intention of academicians especially in an emerging economy like Sri Lanka is still lacking. This study attempts to establish the attitudinal factors that contributes actual e-learning behavior of academicians.
\end{abstract}

Keywords - Attitude, Perceived ease of use, Perceived usefulness, E-learning behaviour, Intention, Higher Education, Sri Lanka, Decomposed Theory of Planned Behaviour (DTPB).

\section{INTRODUCTION}

Information and Communication Technology (ICT) has brought dramatic changes to business, communication, banking, travel, tourism, medicine and education (Atan, 2015). The advances made in telecommunication systems have brought revolutionary changes to education systems, too especially in the teaching and learning methods. Traditional classroom based teaching and learning processes are subject to various constraints, such as inadequate lecture hall size, shortage of furniture, high costs and insufficient time. ICT can help surmount these difficulties and expand

Revised Manuscript Received on December 22, 2019

* Correspondence Author

Mashroofa, Science Library, South Eastern University of Sri Lanka, Oluvil, Sri Lanka. Email: mashroof@seu.ac.lk

Mazuki Jusoh, Graduate School of Management, Management \& Science University, Selangor, Malaysia

Karuthan Chinna, School of Medicine, Faculty of Health and Medical Sciences, Taylor's University, Malaysia the learning opportunities. E-learning (E-L) is the most significant paradigm shift that has taken place in the higher education system across the world (Ganguly, et al., 2010; OECD, 2016; Mbengo, 2014). E-Learning is typically conducted via electronic media, but it is not limited to the WWW (the Internet) (Nkongolo and Westman, 2019). It is defined as "E-Learning is learning which is enhanced, supported, mediated or assessed by the use of electronic media" (Edumadze, 2019). The necessity has arisen for educational institutions to shift the paradigm of in-class learning and teaching to distance learning. Distance learning increases the access to education and e-learning is considered as a value-added service available for open and distant learning. Therefore, e-learning is the most innovative approach or tool applied in open and distant learning even to enhance face-to-face learning. However the poor usage is obvious by the extant literature ( Lakshman and Schubert, 2015; Noh, Abdullah, Teck, \& Hamzah, 2019). Based on this reason, the study pursues to examine the attitudinal factors such as perceived ease of use, perceived usefulness and compatibility on behavioural intention and in turn on the actual usage among the academics in state universities in Sri Lanka.

As academics are the crucial stakeholders in adopting any type of innovations in academic institutions, this empirical study is expected to determine the factors that associate with the behaviour. This will benefit policy makers of University Grants Commission (UGC), university administrations, academicians and researchers in Sri Lankan context and the like developing countries. This is in line with Strategic Management Plan of University Grants Commission 2013-2017 of Sri Lanka. Despite, academicians face challenges most especially in the universities which were under the threshold of civil unrest for three decades, the ICT development is well underway as a part of post war development activities. The E-L trend is becoming more pronounced in Sri Lanka (Fernando, 2011; Abeysekera, 2008; Thowfeek \& Hussin, 2013; Yatigammane 2015; Suraweera 2014). However, the e-learning usage seems very low, Ratnapala (2014) and Suraweera (2014). The usage of e-learning should be motivated not only to enhance the quality of the degrees, but also to quantify the higher learning opportunities of the students who were not admitted to state universities due to limited infrastructure, facilities and government policies, by providing distant learning. 


\section{Objectives of the research}

- To identify the factors associated with the attitude of university academics in using e-learning in Sri Lanka.

- To examine the influence of attitude with behavioural intention and actual behaviour of academics in using e-learning

- To measure the mediating role of behavioural intention (BI) in the association between Attitude (ATT) with actual behaviour

\section{LITERATURE REVIEW AND HYPOTHESES DEVELOPMENT}

From the inception of innovation adoption theories and models, 'attitude' was considered as a crucial factor. TRA developed by Fishbein and Icek Ajzen in 1967 says "behavioral intention of any action is based on ATT and subjective norms (SN)". ATT refers the belief that result of an evaluation of positive and negative consequences of engaging in the behaviour. Technology Acceptance Model (TAM) was developed by Davis in 1989 has replaced attitude by perceived ease of use (PEOU) and perceived usefulness(PU). Then Theory of Planned Behaviour theorized by Ajzen in 1991 also includes attitude in addition to the SN and perceived behavioural control (PBC). Then DTPB developed by Taylor and Todd in 1995 and 2001, has decomposed the main three independent variables such as ATT, SN and PBC control into possible antecedents and they have given room to input any new antecedents. In case of Sri Lankan public university system, government has initiated and completed several projects to enhance the ICT infrastructure, resources and facilitating conditions of the universities. Therefore, poor usage of e-learning system might be mainly due to the attitude of the academicians. Therefore this research study specifically deals with attitudinal factors.

It is widely documented from the reviewed literature that the use of any innovation or new technology, depends on the attitude of individuals. In the literature of behavioral and psychological models, attitude is defined as a key determinant of the intention of actual behavior, (Taylor \& Todd, 1995; Taylor \& Todd, 2001). Attitude towards the behavior or attitude towards the use of technological systems is used as key elements and direct determinants of the intention to use the systems in several studies, (Davis et al., 1989; Taylor \& Todd, 1995; Santos \& Okazaki, 2015; Tarhini et al, 2017). Attitude was decomposed into 'perceived usefulness' (PU), 'perceived ease of use' (PEOU) and compatibility in the decomposed theory of planned behaviour. "Any system user would consider these three aspects", Taylor and Todd, (1995). Santos and Okazaki (2015) added one more variable to the attitudinal belief known as 'relative advantage', but according to Taylor and Todd (2001) as PU supersede 'relative advantage' it was not considered while decomposing attitudinal beliefs. Variables and hypotheses are explained below the conceptual framework.

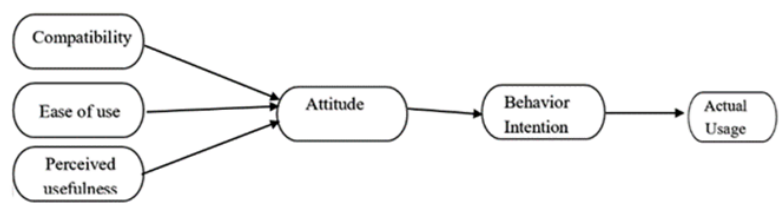

Figure 1. Conceptual model attitudinal belief, behavioural intention and actual behavior constructs (Source: Adapted from DTPB model developed by Taylor \& Todd $(1995,2001)$

\section{Compatibilty}

Compatibility (CA) is defined as "the degree to which technological innovation conforms to previous experiences for to the needs of users" (Rogers, 1983). Along the same lines, Tornatzkey and Klein (1982) emphasized that the adoption of an innovation is most likely when it is compatible with the work and value the system by individuals. Compatibility is also important variable for this study because using E-L should be harmonious with conventional way of teaching and learning in the university and overweigh the advantages. Some studies related to the adoption of E-L have focused on compatibility, (Ajjan \& Hartshorne, 2008) and found significant association with attitude. On the other hand, Santos \& Okazaki (2015) has found insignificant effect. Even though the results were inconsistency, this particular research study includes compatibility to evaluate whether the faculty members have compared E-L with traditional methods. Following this logic, the following hypothesis was proposed: Therefore, each of these factors, influences attitude of the academics in using e-learning.

H1. Compatibility is significantly and positively related to behavioural intentions.

\section{Perceived ease of use (PEOU)}

PEOU refers that how easy to the academics of the university to practice the E-L portal for teaching and learning. The PEOU construct is originally used in the TAM (Davis, 1989), being used in the decomposed TPB as a direct determinant of the attitude. This construct has been used in several studies on E-L with the aim of predicting students' adoption of this tool, (Pituch \& Lee, 2004; Wang \& Wang, 2009; Cheng, 2011). E-learning is considered as an innovative mode of delivery of higher education which is in par with Sri Lanka's vision for 2020; "to be the knowledge hub in the region and a leader in higher education in Asia by 2020". This study is thus inspired the researcher in order to breakdown the existing challenges the country face at present in expanding the higher learning opportunities. Further, PEOU variable is considered as a crucial prognosticator of individual satisfaction even in many studies focused on E-L acceptance and usage, (Tarhini et al., 2017; Ndubsi, 2004; Roca et al., 2006; Pituch \& Lee 2004). Therefore, we hypothesise that:

$H 2$. PEOU is significantly and positively related to Attitude. 


\section{Perceived usefulness (PU)}

In this study PU refers how much the usage of E-L system does support the performance of their teaching. Different studies on internet-based technological, innovative systems adoption in the context of institutions, (Davis et al.,1989; Venkatesh \& Davis, 2000) have used PU as a key determinant of the intention to practice. In relation to the above, Taylor and Todd, (1995) suggest that the attitude towards system use is an important mediator of the indirect association between the intention of use and the perceived usefulness. According to the previous arguments, which suggest the importance of the perception of usefulness as a fundamental direct determinant of the attitude in the framework of the acceptance of innovative technologies, this study also considers it appropriate to propose the inclusion of the construct PU in the research model. Considering the importance of PU in the previous studies, (Ndubisi, 2004; Taylor \& Todd, 1995) to the context of E-L and those studies resulted significant impact on attitude, this particular study also considers PU as one of the direct determinant of Attitude and the following hypothesis was proposed.

H3. Perceived usefulness is significantly and positively related to attitude.

\section{Attitude and behavioural intentions (BI)}

Empirical evidence has shown the relevance of the attitude as an evaluating variable and a direct determinant of the intention to use internet-based systems, Ndubsi, (2004), Ajjan and Hartshorne (2008). In E-L adoption studies, too attitude was an influential factor in determining behavioural intention (Ndubsi, 2004; Tarhini et al., 2017). Anyhow very rarely attitude has insignificant effect with behavioural intention, too (Taylor \& Todd, 2001). Therefore, we have proposed the following hypothesis to test the effect of attitude with behavioural intention:

\section{H4. ATT of academics is positively related to BI.}

\section{Behavioural Intention (BI)}

The application of the variable of intention-to-practice, (Davis et al., 1989; Venkatesh \& Morris, 2000) or behavioral intention, (Fishbein \& Ajzen, 1975; Ajzen, 1991) has been given a key role as direct indicators for measuring actual use of technology. They are also considered BI as quite accurate predictors of future behavior, (Wilson \& Lankton, 2004), justifying the intention to practice as a sufficient approximation to evaluate the adoption of E-L systems, though very rarely (Saade et al., 2008) resulted weak relationship. This brings us to the last hypothesis. These arguments have assisted as the foundation for the development of a theoretical adaptation in research, starting from the original concepts towards the proposed concepts. Once all the constructs have been defined, where the preliminary model with the proposed constructs and their possible causal relationships is observed. This brings us to the last hypothesis:

H5: There is a relationship between Behavioural Intention and Actual Behaviour

$\mathrm{n}$ addition, the mediating effect of behavioural intention between attitude and actual behaviour should be examined. Taylor and Todd (2001) dropped behavioural intention and tested to examine the direct relationship between attitudes with actual behavior. Then the test resulted the prediction of behaviour has been decreased and they concluded that BI plays a significant and essential role, but also crucial practically in predicting power. Based on the aforementioned facts next hypotheses was proposed.

H6: BI mediates the relationship between attitude and actual behaviour

\section{RESEARCH METHODOLOGY}

Quantitative and explorative research method was used. Data were collected from all fifteen Sri Lanka's state universities which are under the control of UGC. Academics of all fifteen universities were considered as population. Total permanent academics of all fifteen universities is 5399, (UGC statistics, 2017). Among them 357 are considered as sample size, by using sample size for a given population size defined by Krejcie and Morgan (1970) as cited in Sekaran and Bougie (2010). Stratified systematic and proportionate sampling technique was used to select sample in order to represent all categories of academics. Questionnaires were administered to collect data from academics of all universities. Reliability and validity of the measures in the construct of each variable were tested. Data analysis was conducted using correlation and regression analysis and structural equation modelling (SEM) to elucidate the hypothesized relationship between variables of E-L actual usage, PEOU, PU, ATT and learners BI (Figure 1).

\section{RESULTS AND DISCUSSION}

\section{Demographic profile of respondents}

Out of the 357 questionnaires sent out, 314 responses were received, at a response rate of $87.95 \%$. This study covered all the 15 universities in Sri Lanka. Among the respondents $52.6 \%$ male and $47.4 \%$ are females. Majority of them $(47 \%)$ are senior lecturers, $41.4 \%$ are lecturers and $11.6 \%$ are professors. Only $44.4 \%$ (less than half) of the respondents currently use the E-L system which was installed and implemented in their respective universities. Considering the e-learning system $77.7 \%$ of the respondents use MOODLE whilst 5.3\% use Content Management system, $17.7 \%$ use Virtual Learning Environment and 3.3\% only use blackboards.

\section{Reliability and validity}

Items in all five main constructs and their antecedents were confirmed for reliability and validity. The Cronbach $\alpha$ value for CA, PEOU, PU, ATT, BI and actual behaviour have Cronbach $\alpha$ values of of $0.772,0.914,0.9030 .872,0.9$ and 0.817 respectively. According to Chinna (2012).The Cronbach alpha values should be more than 0.7 for acceptable scale reliability. All of the constructs have shown the value more than 0.70 , which confirmed the reliability of those constructs.

The Kaiser-Meyer-Olkin for CA, PEOU, PU, ATT, BI and actual behavior are $0.799,0.839,0.912,0.831,0.837$ and 0.795 , respectively. The factor metrics range for compatibility, perceived ease of use, perceived usefulness, attitude, behavioural intention and actual behaviour are $0.620-0.770,0.80-0.90,0.59-0.86,0.78-0.83,0.837-0.911$ and $0.728-0.836$ respectively. The AVE values for CA, PEOU, PU, ATT, BI and actual behaviour $0.544,0.726,0.5,0.618,0.701$ and

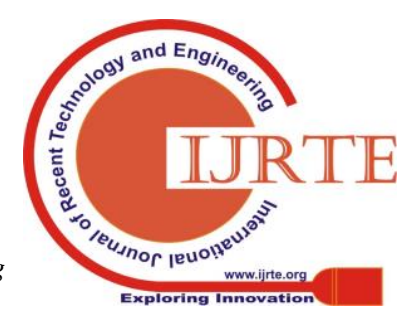


0.535 , respectively.

Results and discussion in terms of the different constructs The conceptual model consists of the variables CA, PEOU, PU, ATT, BI and actual behaviour are expected to be model fit in order to continue advance analysis. The model fit was evaluated by using multiple goodness-of-fit indices. There are seven fit indices measures used were; Goodness-of-Fit Index, CMIN/DF, RMR, GFI, Comparative Fit Index (CFI),
Root Mean Square Residual (RMR), Root Mean Square Error of Approximation (RMSEA), Composite reliability (CR), Average variance extracted (AVE). According to Hair, et al. (2010) and Kline (2005). The following rule was used in model fit evaluation: Chi-square/df $<3$, GFI $>0.9$, AGFI $>0.9$, CFI $>0.9$, RMSEA $<0.08$ values (Hair et al., 2010).

Table 1: Model fit parameters of all 6 based on structural model

\begin{tabular}{ccccccc}
\hline Variable & CMIN/DF & RMR & GFI & TLI & CFI & RMSEA \\
\hline Compatibility & 1.226 & 0.012 & 0.996 & 0.996 & 0.999 & 0.027 \\
\hline Perceived Ease of Use & 1.837 & 0.005 & 0.997 & 0.994 & 0.999 & 0.053 \\
\hline Perceived Usefulness & 2.601 & 0.028 & 0.964 & 0.965 & 0.978 & 0.073 \\
\hline Attitude & 1.548 & 0.007 & 0.995 & 0.994 & 0.998 & 0.043 \\
\hline Behavioural Intention & 1.723 & 0.009 & 0.995 & 0.994 & 0.998 & 0.049 \\
\hline Actual Behaviour & 1.554 & 0.023 & 0.995 & 0.992 & 0.997 & 0.043 \\
\hline
\end{tabular}

According to the above table, the indices for model fit show that all the measurement models of all individual constructs satisfy the threshold values indicated by Hair et al, (2010). Therefore, the overall model fit of the attitudinal belief construct was examined for goodness- of- fit.

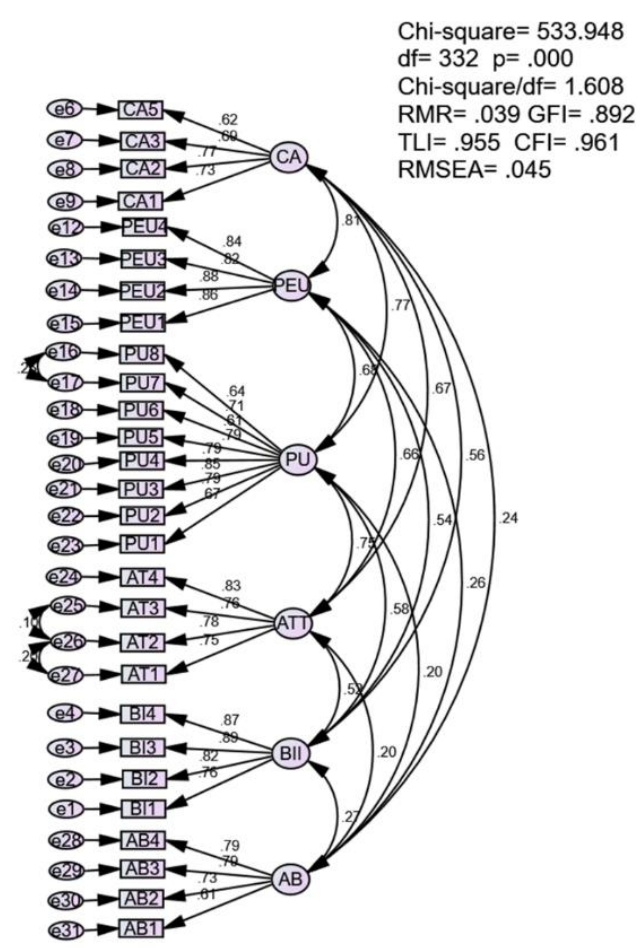

Figure 2: Overall measurement model and the goodness of fit values

The overall model including attitudinal belief constructs (CA, PEOU, PU, ATT), BI and the real usage behaviour is acceptable after correcting three pairs of error terms. This model reaches most of the threshold values Chisquare/df is $1.947<$ than 3 , TLI and CFI are 0.930 and 0.938 respectively and the RMSEA is $0.056<0.08$. In the test of discriminant validly (table 2), pairwise all AVE values were more than the respective R-square value. Hence, there were sufficient discriminant validly between the domains.
Table 2: Di

\begin{tabular}{|l|l|l|l|l|l|l|}
\hline & PU & PEOU & CA & ATT & BI & AB \\
\hline PU & $(0.544)$ & & & & & \\
\hline PEOU & 0.462 & $(0.726)$ & & & & \\
\hline CA & 0.450 & 0.479 & $(0.5)$ & & & \\
\hline ATT & 0.424 & 0.432 & 0.452 & $(0.618)$ & & \\
\hline BI & 0.333 & 0.287 & 0.312 & 0.267 & $(0.701)$ & \\
\hline AB & 0.041 & 0.069 & 0,057 & 0.041 & 0.071 & $(0.535)$ \\
\hline
\end{tabular}

scriminant validity of the variables in the model

Development of a structural model is the second approach in SEM which supports for hypotheses testing and validation. Again the model fit indices were examined and found they have attained the threshold level Chisquare/df is $1.685<$ than 3, TLI and CFI are 0.950 and 0.955 respectively and the RMSEA is $0.048<0.08$. mentioned by Hair et al.(2010) and reveals that the model is fit and recognized as a valuable model based on advance statistic techniques in structural equation modelling. According to Hair et al (2010), if any three or four of the goodness of fit indices are within the threshold then the entire model is acceptable for further analysis. 


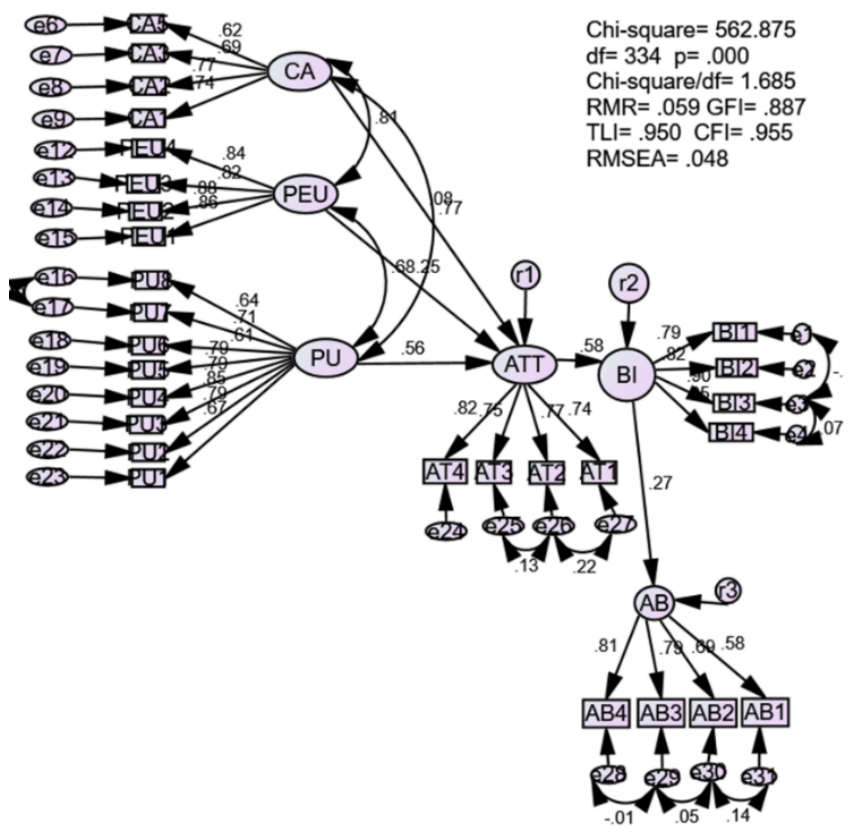

Figure 3: Overall structural model and the goodness of fit values

Hence, final structural model 'correctness' is acceptable (Chinna, 2015). It emphasized that all construct makes a comparable contribution to the final structural model. Therefore it was used to test hypotheses,

Table 3: Regression Weights of Attitudinal Belief Structure

\begin{tabular}{|l|l|l|l|l|l|l|l|}
\hline Path & $\begin{array}{l}\text { Hypoth } \\
\text { eses }\end{array}$ & $\begin{array}{l}\text { Unst. } \\
\text { Reg. } \\
\text { weight }\end{array}$ & S.E. & $\begin{array}{l}\text { Stand. } \\
\text { Reg. } \\
\text { Weight }\end{array}$ & C.R. & $\begin{array}{l}\text { Sig. } \\
\text { level }\end{array}$ & Conclusion \\
\hline ATT <--- CA & H1 & 0.085 & 0.098 & 0.107 & 0.869 & 0.385 & Not supported \\
\hline ATT<--- PEOU & H2 & 0.157 & 0.065 & 0.230 & 2.406 & 0.016 & Supported \\
\hline ATT <--- PU & H3 & 0.473 & 0.083 & 0.536 & 5.715 & 000 & Supported \\
\hline BI <--- ATT & H4 & 0.745 & 0.100 & 0.506 & 7.440 & 000 & Supported \\
\hline AB <--- BI & H5 & 0.243 & 0.078 & 0.204 & 3.112 & 0.002 & Supported \\
\hline
\end{tabular}

Robert, Ho (2016) indicated the CR value should be more than 1.96 at 0.05 significant level and beta value (standard regression estimate should be $>0.2$. According to this threshold, conclusion was made based on the path analysis results.

$\mathrm{H} 1$ tests the association between the compatibility (CA) and the attitude (ATT). The results (Table 3 ) show that there is no any association between attitude and compatibility because standardized regression coefficient of the path relationship is statistically not significant between attitude and Compatibility (Regression Coefficient $r=0.107$, significant level $\mathrm{p}=0.385>0.05$ and $\mathrm{CR}$ value is $0.869<1.96$ ). Thus, $\mathrm{H} 1$ is not supported by the data. This outcome thus resonates with Santos \& Okazaki (2015).

$\mathrm{H} 2$ tests the association between the PEOU and the attitude (ATT). The results (Table 3) show that there is a positive influence between ATT and PU because standardized regression coefficient of the path relationship is statistically significant between ATT and PEOU (Regression Coefficient $\mathrm{r}=$. 065, significant level $\mathrm{p}=0.016>0.05$ ). Thus, $\mathrm{H} 2$ is supported by the data. This result is consistent with that of Davis (1989), Taylor and Todd (1995, 2001), Ajjan and Hartshorne (2008), Al-Alak and Al-Nawas (2011) and Tarhini et al., (2015) but contradicts that of Santos and Okazaki (2015) Venkatesh et al., 2003.

$\mathrm{H} 3$ tests the association between the sub variable perceived usefulness (PU) and the independent variable attitude (ATT). The results (Table 4.48) show that there is a positive influence between ATT and PU because standardized regression coefficient of the path relationship is statistically significant between Attitude and perceived usefulness (Regression Coefficient $\mathrm{r}=.536$, significant level $\mathrm{p}=$ $0.000<0.05)$. Therefore, H3 is supported by the data. The outcome is in par with a few other research (Davis, 1989; Taylor \& Todd, 1995; Pituch \& Lee, 2004; Lee, 2006; Cheng, 2011; Santos \& Okazaki, 2015).

H4 tests the association between ATT and the mediating variable BI. The results (Table 3 ) show that there is a positive influence between attitude and behavioural Intention because standardized regression coefficient of the path relationship is statistically significant between ATT and BI (Regression Coefficient $\quad r=0.506$, significant level $p=0.000<0.05)$. Thus, H4 is supported by the data.

H5 tests the association between BI and the dependent variable $\mathrm{AB}$. The results (Table 3 ) show that there is a positive influence between $\mathrm{AB}$ and $\mathrm{BI}$ because standardized regression coefficient of the path relationship is statistically significant (Regression Coefficient $r=0.204$, significant level $\mathrm{p}=0.002<0.05$ ). Thus, H5 is supported by the data.

\section{Mediating effects of behavioural intention on attitude and actual usage behavior}

To test whether BI mediates the association between ATT and AB, the final SEM model is already examined and resulted that 
standardised regression coefficient of the path relationship between ATT and BI has a significant association at 0.000 level $\mathrm{r}=0.506 \quad(\mathrm{P}=0.000<0.05)$. While, the standardized regression coefficient of the path relationship between $\mathrm{BI}$ and $\mathrm{AB}$ has significant association $\mathrm{r}=0.204$ at 0.002 level $(\mathrm{P}$ $=0.002<0.05)$ too. Hence, mediating effect of BI between $\mathrm{ATT}$ and $\mathrm{AB}$ has to be tested for the further decision on the indirect relationship.

The unstandardized regression indirect effect shows the indirect mediated effect is 0.181 between ATT and AB through BI. The indirect and direct effects were computed using AMOS. Detailed results are shown in Table $4 \&$ table 5 .

Table 4: Unstandardized Indirect Effect

\begin{tabular}{llll}
\hline & ATT & BI & AB \\
\hline BI & .000 & .000 & .000 \\
AB & .181 & .000 & .000 \\
\hline
\end{tabular}

Table 5: Indirect Effects Analysis Using 1000 Bootstrap

\begin{tabular}{|l|ccc|ccc|}
\hline & \multicolumn{3}{|c|}{$95 \%$} & \multicolumn{2}{c|}{ Lower Bound } & \multicolumn{3}{c|}{$95 \%$} & Upper Bound \\
\hline & ATT & BI & AB & ATT & BI & AB \\
\hline BI & .000 & .000 & .000 & .000 & .000 & .000 \\
\hline AB & .049 & .000 & .000 & .314 & .000 & .000 \\
\hline
\end{tabular}

At the $95 \%$ confidence interval for the indirect effect of ATT on AB is (lower=0.049, upper $=0.314$ ). The value of 0 does not fall within this interval. Hence, BI mediates the association between ATT and AB. Therefore, BI is a mediator between ATT and AB. Therefore, H6 is also accepted.

H6. "BI mediates the association between ATT and AB" is supported.

\section{Implications}

Attitude was closely related to PU and PEOU. This highlights the interest of academicians in the benefits and ease that the tool can provide. In particular, the original validation of TAM (Davis, 1989) demonstrated the lack of a significant association between PEOU and ATT but our study has proved that there is a positive association. Any e-learning portal developers and the university administration should consider these two factors when they design and implement e-leaning portals.

This study thus supports strategies for pertinent stakeholders to study the attitudinal factors that effects E-L adoption intention and actual usage with respect to the developing countries like Sri Lanka. There are a few important implications the university administration must heed, especially in terms of policy making and training. Attitudinal change is crucial to make them to use e-learning portals exist in respective universities. This study is carried out covering all Sri Lankan public universities and thus these factors could be considered by all the university administrations as well as by the University Grants Commission, which governs all universities. As attitude is a psychometric factor, it is highly important to motivate the academicians in order to change their mindsets to this new paradigm shift.

\section{CONCLUSIONS}

The remedies proposed to address any shortcomings in E-L must be implemented in all of the public universities. it can be concluded that BI is associated with psychological factors related to individual's attitude. Further the result shows that $\mathrm{AB}$ is influenced mainly by $\mathrm{BI}$. In addition, attitude of academics can be improved by the PU and PEOU. That means academics are more concerned about the benefits as well as the ease. BI can be improved with the positive ATT of academics towards the system, which ultimately would lead to the actual behaviour. Hence, the $A B$ is determined by PU, PEOU and ATT in the attitudinal belief construct. The association between ATT and usage behavior is mediated by the intention.

\section{RECOMMENDATIONS}

Though Compatibility (CA) has a model fit with attitude and the other constructs it did not have any association with attitude. It means that academic staff in the public university system of Sri Lanka does not compare the E-L system with the traditional system but mainly considers the benefits or usefulness of the newer system. Therefore, this may be overlapped with perceived usefulness. The result is contradictory with that of Ajjan and Hardshorne (2008) but is supported by Shih and Fang (2004), and Santos and Okazaki (2015), that CA is not significantly associated with ATT. Taylor and Todd (1995) dropped compatibility as they argued that compatibility surfaces with relative advantage. According to Taylor and Todd (2001), compatibility to attitude was not significant at the DTPB, which is constant with the outcomes of the investigation on the adoption of online teaching (Al-hawari \& Mouakket, 2010; Santos \& Okazaki, 2015). Therefore, while decomposing attitudinal belief it is recommended to exclude CA as the present-day academics are digital natives and digital immigrants and they do not consider compatibility as a matter of importance. This is an important aspect that should be emphasized in the literature to guide future studies. Public universities in Sri Lanka should consider both quality education and the quantity, as university admission is so tough and restricted. It is very important to introduce more degree programmes in order to provide higher education opportunities to those who are qualified but not admitted to universities. The only way to face the challenges of unemployment is to adopt the distant and digital mode of delivering education. Similarly, quality education is essential for creating a knowledge society and ensuring sustainable development. This can only be achieved through adopting innovative technology, as this is the fastest and most accurate way to revise the traditional teaching and learning strategies, work norms and policies.

\section{FUTURE RESEARCH}

This study has covered only one portion of the DTPB. Attitude only can contribute $50.6 \%\left(\mathrm{r}^{2}=0.506\right)$ of behavioural intentions hence the contributions of the belief structures should also be studied. Further research by covering other two constructs normative belief (SN) and the control belief (PBC) is very crucial in order to define the effect of $\mathrm{SN}$ and controlling factors that associate E-L usage in addition to the attitudinal factors, 
Also while decomposing attitudinal factors the future researchers can add other variables, too as the DTPB did not limit the variables and its numbers while decomposing the belief structures.

\section{REFERENCES}

1. Ajjan, H. \& Hardshorne, R.(2008), "Investigating faculty decisions to about web 2.0 technologies: theory and empirical test", Internet and Higher Education, Vol. 11, pp.71-80.

2. Edumadze, J.K.E. (2019), E-Learning At The University Of Cape Coast, Ghana-Are Our Distance Education Students Technologically Ready? The Online Journal of Distance Education and e-Learning, 7(2), 70-81, Retrieved from www.tojdel.net

3. 3.Ganguly, P. (2010). Teaching and Learning of Anatomy in the 21st Century: Direction and the Strategies. The Open Medical Education Journal, 3, 5-10.

4. Mbengo, P. (2014). E-learning adoption by lecturers in selected Zimbabwe State Universities: An application of technology acceptance model. Journal of Business Administration and Education, 6(1), 15-33.

5. Santos, L. M. R. \& Okazaki, S. (2015), "Planned e-learning adoption and occupational socialization in Brazilian higher education", Studies in Higher Education, Vol.1 No. 21, available at: http:// dx.doi.org / $10.1080 / 03075079.2015 .1007940$

6. Suraweera, N., Liew, C., \& Cranefield, J. (2014). Introduction of E-Learning in Information Management (IM) Education in Sri Lanka :The Influence of Social and Cultural Factors. Annual International Conference on Education \& e-Learning. doi:10.5176/2251-1814_EeL14.29

7. Tarhini, A., Hone, K. and Liu, X. (2015), “A Cross -cultural examination of the impact of social, organizational and individual factors on educational technology acceptance between British and Lebanese university students", British Journal of Educational Technology, Vol.46 No.4, pp 739-755., available at: doi: 10.111/ bjet.12169

8. Tarhini, A., Hone, K., Liu, X., Tarhini, T.(2017) Examining the moderating effect of individual-level cultural values on users' acceptance of e-learning in developing countries: a structural equation modelling of an extended technology acceptance model, Interactive Learning Environments, 25:3, 306-328, DOI: 10.1080/10494820.2015.1122635

9. 9.Taylor, S. \& Todd, P.A. (1995a). Understanding Information Technology usage: a test of competing models. Information systems Research.6 (2), 144-176.

10. Taylor, S. \& Todd, P. (1995b).Decomposition and crossover effects in the theory of planned behavior: A study of consumer adoption intentions. International Journal of Research in Marketing.12, 137-155.

11. Thowfeek, M.H \& Hussin, H. (2008).Instructors' Perspective on E -Learning Adoption in Sri Lanka : A preliminary Investigation.6, 124 -129. Retrieved from http://ibimapublishing.com / journals / CIBIMA / volume6 / v6n.

12. Ndubisi, N. O. (2004), "Factors influencing e- learning adoption intention: examining the determinant structure of the decomposed theory of planned behavior constructs", proceedings of HERDSA conference, pp. 251-262, available at https://www.researchgate.net/publication/265240354

13. Ratnapala, S. (2014). Adopting E- Learning for University Education in Sri Lanka -Peradeniya Perspective. Proceedings of the Peradeniya University, (p. 105). Retrieved from http://www.pdn.ac.lk/ipurse/2014/proceeding_book/ED/105.pdf

14. Venkatesh, V., Morris, M. Davis, G.B. \& Davis, F.B. (2003), "User Acceptance of technology toward a unified view”, MIS Quarterly, Vol. 27 No.3, pp.425-478.

15. Venkatesh, V.\& Davis, F. D. (2000), "A theoretical extension of the technology acceptance model: Four longitudinal field studies", Management Science, Vol. 46, No.2, available at:186-204, doi:10.1287/mnsc.46.2.186.11926

16. Saadé, R.G., Tan, W., \& Kira, D. (2008), "Is Usage Predictable Using Belief-Attitude Intention Paradigm?", Issues in Informing Science and Information Technology, Vol. 5, pp. 591-599, available at : http://proceedings.informingscience.org/InSITE2008/IISITv5p591-59 9Saade503.pdf

17. Strategic Management Plan of University Grants Commission 2013-2017 :Vision, Mission \& https://www.ugc.ac.lk/downloads/corporate_plan/corporate\%20plan_ 2013_2017.pdf

18. Chinna, K., and Yuen, C. W. (2012), Statistical Analysis Using SPSS,
Pearson Publishing, Kuala Lumpur: University of Malaya.

19. Chinna, K. and Yuen, C. W. (2015), Statistical Analysis Using SPSS, (2nd ed.), Pearson Publishing, University of Malaya, Kuala Lumpur

20. Hair, J.F., Black, W.C., Babin, B.J., and Anderson, R.E. (2010), Multivariate Data Analysis, (7th ed.), Prentice Hall, Upper Saddle River, New Jersey.

21. Lakshman and Schubert (2015), Transfering knowledge or teaching obedience:do obedient students learn better, European Scientific Journal, 11(4), 280-293

22. Noh, N., Abdullah, N., Teck, W., \& Hamzah, M. (2019). Cultivating Blended Learning in Teaching and Learning: Teachers' Intrinsic and Extrinsic Readiness in Malaysia. International Journal of Academic Research in Business and Social Sciences, 8(2), 2.

23. Pituch, K. A. and Lee, Y.K. (2004), "The influence of system characteristics on e-learning use", Computer and Education, Vol. 44, No 2.

24. Wang, W.-T., and Wang, C.-C. (2009), “An empirical study of instructor adoption of web-based learning systems", Computers \& Education, Vol.53 no.3, pp. 761-774.

25. Wilson, E.V and Lankton, N.K.(2004), "Modeling Patients" Acceptance of Provider-delivered E-health", Journal of the American Medical Informatics Association, Vol.11 No.4, pp. 241-248, available at : DOI: 10.1197/jamia.M1475

26. Tornatzky, L. G. and Klein, K.J. (1982), "Innovation Characteristics and Innovation Adoption-Implementation: A Meta-Analysis of Findings", IEEE Transactions on Engineering Management, Vol. 29 No.1, pp. 28-45.

27. Ranasinghe, P., Wickramasinghe, S., Pieris, W., Karunathilake, I., \& Constantine, G. (2012). Computer literacy among first year medical students in a developing country: A cross sectional study. BMC Research Notes, 5(504). Retrieved from http://www.scopus.com/inward/record.url?eid=2-s2.0-84866172168 \&partnerID=40\&md5=dfca9f1995d90608929f1203cba836bd

28. 27.Yatigammana, M. R., Johar, M. G., \& Gunawardh. (2013). Postgraduate Students' Perceived E-Learning Acceptance: Model Validation. International Journal of Asian Business and Information Management, 4(3), 51-60. doi:10.4018/jabim.2013070105

29. Fishbein, M., and Ajzen, I. (1975), Belief, attitude, intention and behavior: An introduction theory and research. Reading, Addison-Wesley: MA 